\title{
Aspergillus Section Fumigati Pneumonia and Oxalate Nephrosis in a Foal
}

\author{
Jasmine Hattab ${ }^{1}$, Antonella Vulcano ${ }^{2}$, Silvia D'Arezzo ${ }^{2}$, Fabiana Verni ${ }^{3}$, Pietro Giorgio Tiscar ${ }^{1}$ (I), \\ Giovanni Lanteri ${ }^{4}\left(\mathbb{D}\right.$, Emil Gjurcevic ${ }^{5}$, Umberto Tosi $^{1}$ and Giuseppe Marruchella ${ }^{1} * *(1)$
}

1 Faculty of Veterinary Medicine, University of Teramo, Loc. Piano d'Accio, 64100 Teramo, Italy; jhattab@unite.it (J.H.); pgtiscar@unite.it (P.G.T.); utosi@unite.it (U.T.)

2 Laboratorio di Microbiologia Banca Biologica e Cell Factory, Istituto Nazionale Malattie Infettive "Lazzaro Spallanzani", via Portuense 292, 00149 Rome, Italy; antonella.vulcano@inmi.it (A.V.); silvia.darezzo@inmi.it (S.D.)

3 Veterinary Practitioner, Loc. Convento, 64023 Teramo, Italy; f.verni@yahoo.it

4 Department of Chemical, Biological, Pharmaceutical and Environmental Sciences, Viale G. Palatucci, 98168 Messina, Italy; giovanni.lanteri@unime.it

5 Department for Biology and Pathology of Fish and Bees, Faculty of Veterinary Medicine, University of Zagreb, Heinzelova 55, 10000 Zagreb, Croatia; egjurcevic@vef.hr

* Correspondence: gmarruchella@unite.it; Tel.: +39-0861-266932

Citation: Hattab, J.; Vulcano, A.; D’Arezzo, S.; Verni, F.; Tiscar, P.G.; Lanteri, G.; Gjurcevic, E.; Tosi, U.; Marruchella, G. Aspergillus Section Fumigati Pneumonia and Oxalate Nephrosis in a Foal. Pathogens 2021, 10, 1087. https://doi.org/10.3390/ pathogens 10091087

Academic Editor: László Kredics

Received: 3 August 2021

Accepted: 24 August 2021

Published: 26 August 2021

Publisher's Note: MDPI stays neutral with regard to jurisdictional claims in published maps and institutional affiliations.

Copyright: () 2021 by the authors. Licensee MDPI, Basel, Switzerland. This article is an open access article distributed under the terms and conditions of the Creative Commons Attribution (CC BY) license (https:// creativecommons.org/licenses/by/ $4.0 /)$.

\begin{abstract}
Equine pulmonary aspergillosis is a rare deep mycosis often due to the hematogenous spread of hyphae after gastrointestinal tract disease. We describe herein the main clinic-pathological findings observed in a foal, which spontaneously died after showing diarrhea and respiratory distress. Necropsy and histopathological investigations allowed to diagnose pulmonary aspergillosis, which likely developed after necrotic typhlitis-colitis. Biomolecular studies identified Aspergillus section Fumigati strain as the causative agent. Notably, severe oxalate nephrosis was concurrently observed. Occasionally, oxalate nephropathy can be a sequela of pulmonary aspergillosis in humans. The present case report suggests that the renal precipitation of oxalates can occur also in horses affected by pulmonary aspergillosis and could likely contribute to the fatal outcome of the disease.
\end{abstract}

Keywords: horse; pulmonary aspergillosis; Aspergillus section Fumigati; oxalate nephrosis

\section{Introduction}

Aspergillus species are worldwide-distributed filamentous fungi (mold) which thrive in the soil as saprophytes and occasionally infect animals as opportunistic pathogens [1]. Equine aspergillosis is an uncommon but severe respiratory disease which can affect the sinonasal cavities, the guttural pouches or the lung parenchyma [2]. As a general rule, an immunosuppressive state and host-debilitating conditions predispose to fungal diseases, including aspergillosis. Horses usually become infected through the inhalation of fungal spores. Nevertheless, equine pulmonary aspergillosis (EPA) is often characterized by multifocal-to-disseminated embolic lesions which result from the hematogenous spread of hyphae after acute enteritis [2,3].

Aspergillus sp. can synthesize oxalic acid, which reacts with blood and tissue calcium to precipitate as oxalate crystals, at physiologic $\mathrm{pH}$ values [4]. In humans, the demonstration of such crystals in cytology specimens (e.g., in sputum) is useful to diagnosing Aspergillus infections, most commonly the Aspergillus niger group [5]. Likewise, the precipitation of oxalates within the foci of an Aspergillus infection has been reported in veterinary medicine (mostly in avian species). In a recent retrospective study, Payne et al. [6] observed the deposition of oxalates in 14 out of 38 cases of aspergillosis (Aspergillus sp., Aspergillus fumigatus, Aspergillus niger, Aspergillus versicolor), including 2 out of 15 horses.

We describe herein the peculiar clinic-pathological findings observed in a foal affected by pulmonary aspergillosis and oxalate nephrosis. 


\section{Case Description}

The present case occurred in a Quarter Horse breed, 10-month-old male foal which belonged to a stable housing a total of 10 animals (five mares and five young horses less than two-years-old) in central Italy. The animal under study was kept in a single box provided with an external paddock and was fed with hay ad libitum and flaked feed. The foal was treated with a broad-range anthelmintic drug (ivermectin, Eqvalan ${ }^{\circledR}$, Boehringer Ingelheim Animal Health, Milan, Italy) and vaccinated twice for influenza and tetanus at six and seven months of age (Equilis Prequenza Te ${ }^{\circledR}, \mathrm{MSD}$ Animal Health, Milton Keynes, UK).

During the first decade of January 2020, the foal suddenly got prostrated, out of food and tachypneic. Within $24 \mathrm{~h}$, the clinical picture severely worsened, with fever $\left(42{ }^{\circ} \mathrm{C}\right)$, dyspnea, tachycardia and profuse watery diarrhea. At that time, the foal was treated with isotonic fluids (Ringer's lactate, 15-20 L/die i.v.), antimicrobials (benzylpenicillin plus dihydrostreptomycin, Combiotic ${ }^{\circledR}$, ACME srl, Cavriago, Italy, $10 \mathrm{~mL} /$ die i.m.), vitamin B complex (Dobetin B1-10000 ${ }^{\circledR}$, Ecuphar Italia srl, Milan, Italy $10 \mathrm{~mL} /$ die i.m.) and diosmectite (Smigol, ACME srl, Cavriago, Italy, $150 \mathrm{~g} / \mathrm{BID}$ per os). However, the clinical signs further worsened, and the foal spontaneously died $48 \mathrm{~h}$ after the onset of the disease and was then necropsied.

A wide range of tissue samples (stomach, intestine, spleen, liver, kidneys, lungs, heart, lymph nodes) was promptly fixed in $10 \%$ neutral buffered formalin, embedded in paraffin and routinely processed for histopathological investigations (hematoxylin and eosin stain, H\&E). Due to the precarious field conditions, no further sampling for microbiological investigations was carried out.

Grossly, the most relevant lesions affected the large intestine and the lungs. In more detail, the mucosa of the cecum and colon appeared necrotic, with abundant watery content filling their lumina. Microscopically, the intestinal mucosa was diffusely necrotic, infiltrated by inflammatory cells (mainly polymorphonuclear cells) and covered by bacterial aggregates; the lamina propria was strongly hyperemic, with scattered inflammatory cells seen also in this layer.

Both lungs appeared severely hyperemic and edematous. Moreover, disseminated nodules (2-5 $\mathrm{mm}$ in diameter) were appreciated at palpation throughout the lung parenchyma. Microscopically, pulmonary nodules appeared intensely hyperemic, the alveolar walls were thickened and congested. Foci of necrosis and hemorrhages were also seen, infiltrated by macrophages and polymorphonuclear cells. A huge number of branching septate fungal filaments, morphologically resembling Aspergillus sp., were detected inside the alveolar lumina, within the necrotic-hemorrhagic areas and the blood vessels (Figure 1). When subpleural nodules were investigated, the inflammatory reaction also involved the pleural surface, with numerous hyphae embedded within the fibrinous exudate which covered the visceral pleura.
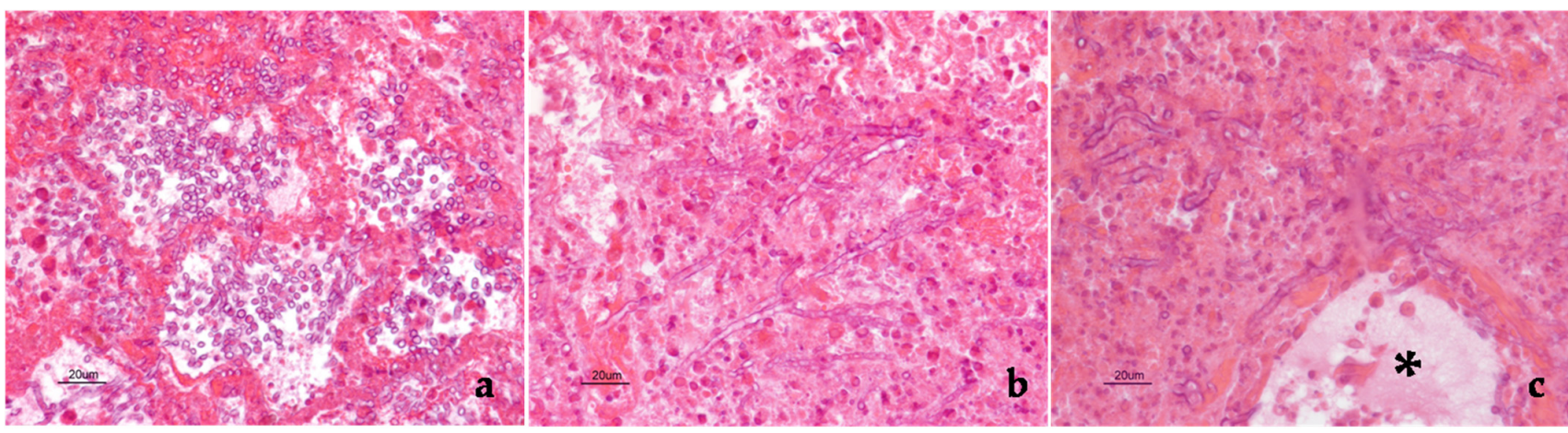

Figure 1. Foal. Pulmonary nodule. Several fungi were present inside the alveolar lumina (a), within necrotic-hemorrhagic foci (b) as well as in the blood vessel wall (black asterisk indicates the lumen of the same vessel). In some microscopic fields $(\mathbf{b}, \mathbf{c})$, dichotomous branching hyphae were seen. Hematoxylin and eosin stain. Final magnification $400 \times$. 
Considering the microscopic findings, a formalin-fixed nodule was submitted for biomolecular study, aiming to identify the causative agent. A polymerase chain reaction assay targeting a highly conserved region of the $28 \mathrm{~S}$ large ribosomal subunit (28S rDNA) was used as screening for the detection of clinically relevant fungi [7]. Section-level identification was achieved by sequence analysis followed by nucleotide BLAST analysis (https:/ / blast.ncbi.nlm.nih.gov / Blast.cgi; accessed on: 29 July 2021). The results showed a 99\% identity with Aspergillus fumigatus (GenBank: MH869824.1).

Remarkably, severe and extensive nephrosis was observed. Translucent and fanshaped crystals filled almost all renal tubules, with no evidence of nephritis or fibrosis (Figure 2). The morphology of such crystals closely resembled that of calcium oxalates. The observation of H\&E-stained sections under polarized light showed that crystals were strongly birefringent (Figure 3), thus confirming that they consisted of calcium oxalates. Careful examinations of the slides ruled out the deposition of oxalates in other tissues and organs.
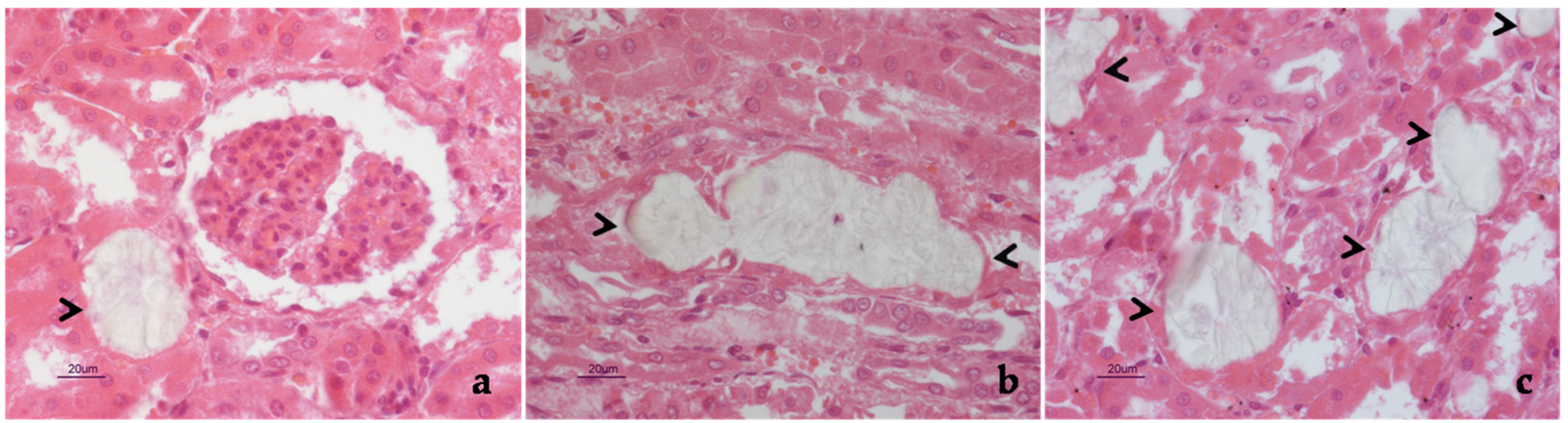

Figure 2. Foal. Kidney. Typical fan-shaped, oxalate crystals were seen in the lumina of renal tubules, both in transverse (a) and longitudinal (b) section (black arrowheads). The precipitation of oxalates affected most of renal tubules (c, black arrowheads), which appeared distended, their epithelium being no longer detectable (a-c). Hematoxylin and eosin stain. Final magnification $400 \times$.

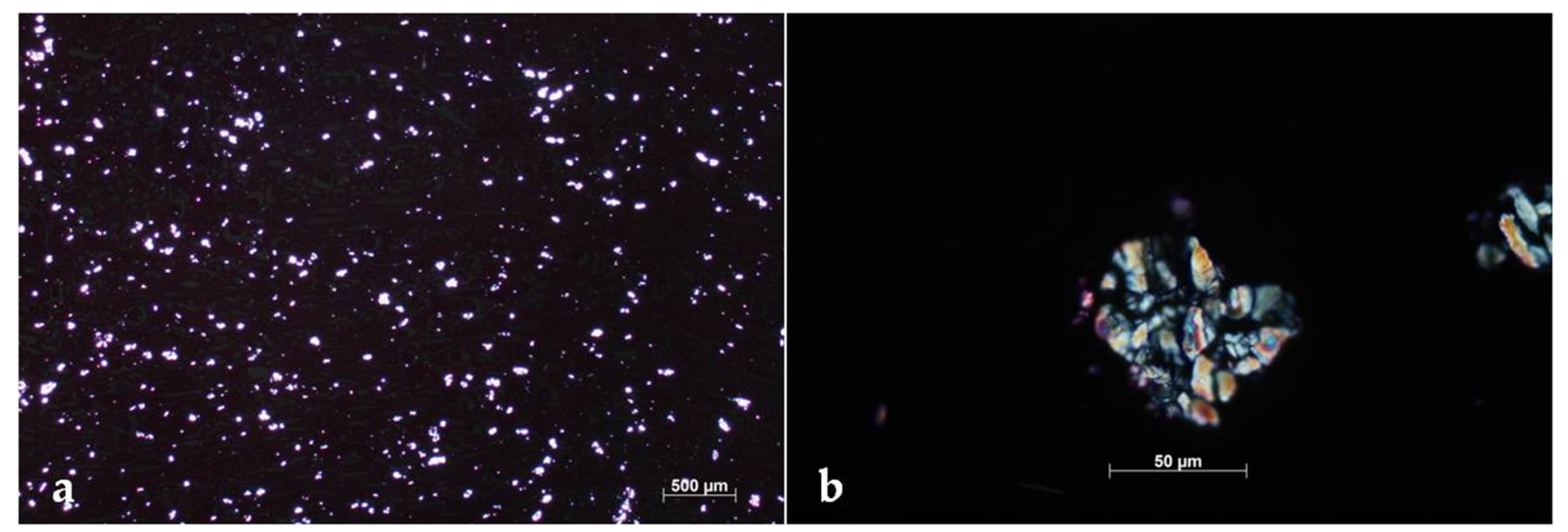

Figure 3. Foal. Kidney. At very low magnification, the precipitation of countless oxalate crystals was evident (a). At higher magnification, the typical birefringence, with radiating spokes, could be appreciated (b). Polarized light microscopy, hematoxylin and eosin stain. Final magnification $25 \times(\mathbf{a}), 400 \times(\mathbf{b})$.

Altogether, clinic-pathological and laboratory findings allowed us to diagnose Aspergillus section Fumigati strain pneumonia with concurrent severe oxalate nephrosis. 


\section{Discussion}

EPA is widely recognized as a rare disease condition. In the largest case series currently available, Sweeney and Habecker [8] reported an estimated prevalence lower than $0.04 \%$, i.e., 29 out of 73,000 horses admitted to a veterinary teaching hospital. Up to date, a total of 71 EPA cases have been recorded on the MEDLINE database (http:/ /www.ncbi.nlm.nih. gov / pubmed/; accessed on: 16 July 2021) entering "horse, lung, aspergillosis" as keywords (see Table 1 for further details).

Table 1. Cases of pulmonary aspergillosis so far reported in the horse.

\begin{tabular}{|c|c|c|c|c|c|}
\hline $\begin{array}{l}\text { Number of } \\
\text { EPA Cases }\end{array}$ & Predisposing Factors & Aspergillus Species & $\begin{array}{l}\text { Sites of Infection } \\
\text { (Other Than Lung) }\end{array}$ & $\begin{array}{l}\text { Sites of Oxalates } \\
\text { Precipitation }\end{array}$ & Reference \\
\hline 19 & $\begin{array}{c}\text { Enterocolitis }(n=14) \text {, } \\
\text { intensive corticosteroid } \\
\text { treatment }(n=2), \\
\text { urolithiasis }(n=1), \\
\text { myelogenous } \\
\text { leukemia }(n=1), \\
\text { hemangiosarcoma }(n=1)\end{array}$ & $\begin{array}{c}\text { Aspergillus sp. }(n=17), \\
\text { Aspergillus } \\
\text { fumigatus }(n=2)\end{array}$ & $\begin{array}{l}\text { Kidneys }(n=2) \text {, } \\
\text { brain }(n=1)\end{array}$ & Not reported & [3] \\
\hline 11 & Not reported & $\begin{array}{l}\text { Aspergillus sp. }(n=11) \\
\text { Aspergillus fumigatus } \\
(n=2), \text { Aspergillus } \\
\text { glaucus }(n=1) \\
\text { Aspergillus flavus }(n=1)\end{array}$ & $\begin{array}{c}\text { Colon }(n=1), \text { kidney } \\
(n=1), \text { heart }(n=1), \\
\text { skeletal muscle }(n=1), \\
\text { guttural pouches }(n=1)\end{array}$ & $\begin{array}{l}\text { Lungs }(n=1) \text { and } \\
\text { kidneys }(n=2)\end{array}$ & [6] \\
\hline 29 & $\begin{array}{l}\text { Loss of integrity of the } \\
\text { gastrointestinal } \\
\text { tract }(n=25)\end{array}$ & Aspergillus sp. & $\begin{array}{l}\text { Not specified } \\
\text { organs }(n=12)\end{array}$ & Not reported & [8] \\
\hline 2 & None & Aspergillus fumigatus & $\begin{array}{l}\text { Kidneys, myocardium, } \\
\text { brain }\end{array}$ & Not reported & [9] \\
\hline 1 & Cushing's syndrome & Aspergillus sp. & None & Not reported & [10] \\
\hline 1 & Leukemia & Aspergillus sp. & Gut & Not reported & [11] \\
\hline 1 & $\begin{array}{l}\text { Exposure to high } \\
\text { spore count }\end{array}$ & Aspergillus niger & None & Not reported & [12] \\
\hline 1 & $\begin{array}{c}\text { Ehrlichia risticii infection, } \\
\text { acute enteritis }\end{array}$ & & None & Not reported & [13] \\
\hline 1 & $\begin{array}{l}\text { Volvulus of the colon } \\
\text { and peritonitis }\end{array}$ & Aspergillus sp. & Heart & Not reported & [14] \\
\hline 2 & $\begin{array}{c}\text { Sarcocystis neurona } \\
\text { infection }(n=1) \text {, small } \\
\text { intestine } \\
\text { obstruction }(n=1)\end{array}$ & Aspergillus sp. & None & Not reported & [15] \\
\hline 1 & Unknown & Aspergillus fumigatus & None & Not reported & [16] \\
\hline 1 & Enterocolitis & Aspergillus fumigatus & Colon & Not reported & [17] \\
\hline 1 & $\begin{array}{c}\text { Myelomonocytic } \\
\text { leukemia }\end{array}$ & Aspergillus sp. & None & Not reported & [18] \\
\hline
\end{tabular}

Gastrointestinal disorders appear as the most common predisposing factor (43 cases, i.e., $60.56 \%$ ). The identification of the causative agent often does not go beyond the genus level; however, Aspergillus fumigatus is the most commonly identified species in EPA (8 cases, i.e., $11.26 \%$ ). Oxalate crystals have been only reported in two horses.

According to what was repeatedly reported in the literature, the present case of EPA most likely occurred after acute typhlitis-colitis, which disrupted the mucosal barrier of the large intestine and allowed the hematogenous spreading of fungi. The presence of disseminated lesions scattered throughout the parenchyma of both lungs, along with the detection of hyphae in the blood vessels, further support such a pathogenetic hypothesis. Slocombe and Slauson [3] hypothesized a synergistic relationship between acute entero- 
colitis by Salmonella sp. and EPA, although they often isolated different bacterial species from the intestine of horses affected by pulmonary aspergillosis (namely, Escherichia coli, Klebsiella sp., Staphylococcus aureus, Clostridium perfringens, Proteus sp., Actinobacillus equuli). In the present case report, pathological findings argue in favor of a bacterial etiology of typhlitis-colitis, which unfortunately could not be further investigated.

In veterinary medicine, oxalate nephrosis is frequently observed in dogs and cats due to ethylene glycol toxicity, as well as in small ruminants after the ingestion of plants of various genera (e.g., Oxalis, Rumex) which can accumulate oxalates. The production of oxalic acid is a common feature of filamentous fungi and is catalyzed by oxaloacetate hydrolase (OAH) [19]. In particular, some fungi (e.g., Aspergillus niger, Aspergillus flavus) can produce large amounts of oxalates on feedstuffs, which may represent another potential cause of poisoning [20]. Aspergillus fumigatus is less commonly recognized as an oxalateproducing pathogen [21]. It would be interesting to investigate the expression and activity of Aspergillus section Fumigati OAH to know whether differences exist in oxalate production among strains and/or under different culture conditions.

Generally, the horse is considered resistant to oxalate-induced nephrosis. In this animal species, acute poisoning results from exposure to very high dosage of oxalates in food and causes fatal gastroenteritis, while prolonged exposure to that chemical is known to induce osteodystrophia fibrosa [20]. Hypothetically, the food may have been the source of poisoning in the case described herein. However, this scenario is unlikely, considering that all the other horses living in the same stable and fed with the same hay and feedstuff did not show any clinical signs. Moreover, the subsequent analysis of the hay and feedstuffs demonstrated that the level of fungi and mycotoxin contamination was in the range of normality (data not shown).

Reasonably, we consider that oxalate nephrosis occurred as a secondary event after mycotic pneumonia. In this respect, the timing of pulmonary and renal lesions, which both developed in a short period, argues in favor of a direct pathogenetic link between an Aspergillus infection and oxalate deposition in renal tubules. Moreover, fatal cases of oxalate nephrosis occurred in humans after pulmonary Aspergillus niger group infection [22-29]. Likewise, cases of renal oxalosis have been rarely documented in wild ruminants, namely an elk (Cerous elaphus nelsoni) affected by Aspergillus fumigatus pneumonia [30] and a white tail deer (Odocoileus virginianus) with pneumonia and encephalitis caused by Aspergillus fumigatus [31].We remark that in wild ruminants, as well as in several human cases, the renal precipitation of oxalate crystals was not associated with the local infection by Aspergillus sp., and that oxalates were not always detected in lung lesions. Therefore, we speculate that oxalates, which are produced in the pulmonary foci of an Aspergillus infection, can reach the renal parenchyma through the bloodstream accumulating in the renal tubules, where the microenvironment is optimal for their precipitation.

As far as the horse is concerned, the presence of oxalate crystals has been reported only in two cases of aspergillosis (see Table 1 for details). In the first case, both fungi and oxalates were present in lungs and kidneys. In the second case, oxalates were seen in the renal parenchyma, while they remained undetected in the site of Aspergillus sp. infection (i.e., lung). In both cases, the renal deposition of oxalates was restricted to a single tubule, thus being of poor clinical significance [6].

\section{Conclusions}

The present case report supports that EPA should be suspected whenever a severe respiratory syndrome occurs after a gastrointestinal tract disease, particularly when antimicrobials prove to be ineffective [8]. Aspergillus fumigatus is the most commonly documented cause of EPA, although the identification of the causative agent often remains at the genus level. In this respect, biomolecular techniques provide useful tools in identifying the pathogen, even when a fungal culture cannot be performed. Finally, oxalate nephrosis can represent a severe, clinically relevant sequela of EPA-as occasionally observed in human medicine- thus likely contributing to the fatal outcome of the disease. 
Author Contributions: Pathological investigations, J.H., G.L., E.G. and G.M.; clinical management of the animal under study, F.V. and U.T.; biomolecular investigations, S.D. and A.V.; supervision, writing-review and editing, G.M., J.H. and P.G.T. All authors have read and agreed to the published version of the manuscript.

Funding: This research received no external funding.

Institutional Review Board Statement: Ethical review and approval were waived for this study. The present case report involved a client-owned animal, demonstrated a high standard of veterinary care and involved informed client consent.

Informed Consent Statement: Not applicable.

Data Availability Statement: No new data were created or analyzed in this study. Data sharing is not applicable to this article.

Acknowledgments: The authors gratefully thank Alfreda Tonelli for kindly revising the English format of the manuscript.

Conflicts of Interest: The authors declare no conflict of interests.

\section{References}

1. Seyedmousavi, S.; Guillot, J.; Arné, P.; de Hoog, G.S.; Mouton, J.W.; Melchers, W.J.; Verweij, P.E. Aspergillus and aspergilloses in wild and domestic animals: A global health concern with parallels to human disease. Med. Mycol. 2015, 53, 765-797. [CrossRef] [PubMed]

2. Cafarchia, C.; Figueredo, L.A.; Otranto, D. Fungal diseases of horses. Vet. Microbiol. 2013, 167, 215-234. [CrossRef] [PubMed]

3. Slocombe, R.F.; Slauson, D.O. Invasive pulmonary aspergillosis of horses: An association with acute enteritis. Vet. Pathol. 1988, 25, 277-281. [CrossRef] [PubMed]

4. Yoshioka, I.; Kobayashi, K.; Kirimura, K. Overexpression of the gene encoding alternative oxidase for enhanced glucose consumption in oxalic acid producing Aspergillus niger expressing oxaloacetate hydrolase gene. J. Biosci. Bioeng. 2020, 129, $172-176$. [CrossRef] [PubMed]

5. Lee, S.H.; Barnes, W.G.; Schaetzel, W.P. Pulmonary aspergillosis and the importance of oxalate crystal recognition in cytology specimens. Arch. Pathol. Lab. Med. 1986, 110, 1176-1179. [PubMed]

6. Payne, C.L.; Dark, M.J.; Conway, J.A.; Farina, L.L. A retrospective study of the prevalence of calcium oxalate crystals in veterinary Aspergillus cases. J. Vet. Diagn. Investig. 2017, 29, 51-58. [CrossRef] [PubMed]

7. Sandhu, G.S.; Kline, B.C.; Stockman, L.; Roberts, G.D. Molecular probes for diagnosis of fungal infections. J. Clin. Microbiol. 1995, 33, 2913-2919. [CrossRef] [PubMed]

8. Sweeney, C.R.; Habecker, P.L. Pulmonary aspergillosis in horses: 29 cases (1974-1997). J. Am. Vet. Med. Assoc. 1999, $214,808-811$.

9. Headley, S.A.; de Carvalho, P.H.; Cunha Filho, L.F.; Yamamura, A.A.; Okano, W. Equine pulmonary aspergillosis with encephalitic, myocardial, and renal dissemination. Mycopathologia 2014, 177, 129-135. [CrossRef]

10. Carrasco, L.; Mendez, A.; Jensen, H.E. Chronic bronchopulmonary aspergillosis in a horse with Cushing's syndrome. Mycoses 1996, 39, 443-447. [CrossRef] [PubMed]

11. Buechner-Maxwell, V.; Zhang, C.; Robertson, J.; Jain, N.C.; Antczak, D.F.; Feldman, B.F.; Murray, M.J. Intravascular leukostasis and systemic aspergillosis in a horse with subleukemic acute myelomonocytic leukemia. J. Vet. Intern. Med. 1994, 8, $258-263$. [CrossRef] [PubMed]

12. Carrasco, L.; Tarradas, M.C.; Gómez-Villamandos, J.C.; Luque, I.; Arenas, A.; Méndez, A. Equine pulmonary mycosis due to Aspergillus niger and Rhizopus stolonifer. J. Comp. Pathol. 1997, 117, 191-199. [CrossRef] [PubMed]

13. Hattel, A.L.; Drake, T.R.; Anderholm, B.J.; McAllister, E.S. Pulmonary aspergillosis associated with acute enteritis in a horse. J. Am. Vet. Med. Assoc. 1991, 199, 589-590. [PubMed]

14. Pace, L.W.; Wirth, N.R.; Foss, R.R.; Fales, W.H. Endocarditis and pulmonary aspergillosis in a horse. J. Vet. Diagn. Investig. 1994, 6, 504-506. [CrossRef]

15. Johnson, P.J.; Moore, L.A.; Mrad, D.R.; Turk, J.R.; Wilson, D.A. Sudden death of two horses associated with pulmonary aspergillosis. Vet. Rec. 1999, 145, 16-20. [CrossRef]

16. Long, J.R.; Mitchell, L. Pulmonary aspergillosis in a mare. Can. Vet. J. 1971, 12, 16-18. [PubMed]

17. Thirion-Delalande, C.; Guillot, J.; Jensen, H.E.; Crespeau, F.L.; Bernex, F. Disseminated acute concomitant aspergillosis and mucormycosis in a pony. J. Vet. Med. A Physiol. Pathol. Clin. Med. 2005, 52, 121-124. [CrossRef] [PubMed]

18. Blue, J.; Perdrizet, J.; Brown, E. Pulmonary aspergillosis in a horse with myelomonocytic leukemia. J. Am. Vet. Med. Assoc. 1987, 190, 1562-1564.

19. Dutton, M.V.; Evans, C.S. Oxalate production by fungi: Its role in pathogenicity and ecology in the soil environment. Can. J. Microbiol 1996, 42, 881-895. [CrossRef]

20. Maxie, M.G.; Newman, S.J. Urinary system. In Jubb, Kennedy E Palmer's Pathology of Domestic Animals, 5th ed.; Maxie, M.G., Ed.; Saunders Elsevier: Philadelphia, PA, USA, 2007; Volume 2, pp. 523-654. 
21. Maeno, T.; Sasaki, M.; Shibue, Y.; Mimura, K.; Oka, H. Calcium oxalate in the sputum may aid in the diagnosis of pulmonary aspergillosis: A report of two cases. Med. Mycol. Case Rep. 2015, 8, 32-36. [CrossRef]

22. Severo, L.C.; Londero, A.T.; Geyer, G.R.; Picon, P.D. Oxalosis associated with an Aspergillus niger fungus ball. Report of a case. Mycopathologia 1981, 73, 29-31. [CrossRef] [PubMed]

23. Metzger, J.B.; Garagusi, V.F.; Kerwin, D.M. Pulmonary oxalosis caused by Aspergillus niger. Am. Rev. Respir. Dis. 1984, 129, 501-502. [CrossRef] [PubMed]

24. Ghio, A.J.; Peterseim, D.S.; Roggli, V.L.; Piantadosi, C.A. Pulmonary oxalate deposition associated with Aspergillus niger infection An oxidant hypothesis of toxicity. Am. Rev. Respir Dis. 1992, 145, 1499-1502. [CrossRef]

25. Roehrl, M.H.; Croft, W.J.; Liao, Q.; Wang, J.Y.; Kradin, R.L. Hemorrhagic pulmonary oxalosis secondary to a noninvasive Aspergillus niger fungus ball. Virchows Arch. 2007, 451, 1067-1073. [CrossRef]

26. Cho, C.; Asuncion, A.; Tatum, A.H. False-positive antineutrophil cytoplasmic antibody in aspergillosis with oxalosis. Arch. Pathol. Lab. Med. 1995, 119, 558-561. [PubMed]

27. Vaideeswar, P.; Sakhdeo, U.M. Pulmonary aspergilloma with renal oxalosis: Fatal effect at a distance. Mycoses 2009, 52, $272-275$. [CrossRef] [PubMed]

28. Kuwabara, H.; Shibayama, Y. Pulmonary aspergilloma with prominent oxalate deposition. Indian J. Pathol. Microbiol. 2012, 55, 589-590. [CrossRef] [PubMed]

29. Trujillo, H.; Fernández-Ruiz, M.; Gutiérrez, E.; Sevillano, Á.; Caravaca-Fontán, F.; Morales, E.; López-Medrano, F.; Aguado, J.M.; Praga, M.; Andrés, A. Invasive pulmonary aspergillosis associated with COVID-19 in a kidney transplant recipient. Transpl. Infect. Dis. 2021, 23, e13501. [CrossRef] [PubMed]

30. Jae-Hoon, K.; Kyung-Il, K.; Won-Il, K.; Hyun-Joo, S.; Sang-Kyung, L.; Young-Hwa, J. Pulmonary Aspergillosis and Renal Oxalosis in an Elk. Korean J. Vet. Res. 2002, 42, 383-387.

31. Wyand, D.S.; Langheinrich, K.; Helmboldt, C.F. Aspergillosis and renal oxalosis in a white-tailed deer. Case history. J. Wildl. Dis. 1971, 7, 52-56. [CrossRef] 